\title{
Fatigue Life Evaluation For Wind Turbine Blade Based on Multistage Loading Accumulative Damage Theory
}

\author{
Zhang Leian ${ }^{*}, 1,2,3$, Huang Xuemei ${ }^{1}$ and Yuan Guangming ${ }^{1}$ \\ ${ }^{1}$ School of Mechanical Engineering, Shandong University of Technology, Zibo, 255049, China \\ ${ }^{2}$ School of Mechanical and Electrical Engineering, China University of Mining \& Technology, Xuzhou, Jiangsu, \\ 221116, China \\ ${ }^{3}$ Lianyungang Zhongfu Lianzhong Composite Group Co., Ltd, Lianyungang, 222000, China
}

\begin{abstract}
The fatigue life of MW wind turbine blade was assessed by applying theoretical calculation and test verification. Firstly, the fatigue characteristic curve of FRP material was obtained based on Palmgren-Miner damage theory. Furthermore, The fatigue life of Aeroblade1.5-40.3 wind turbine blade using multistage loading accumulative damage theory could be evaluated over 20 years accordingly. Then the coordinate system of wind turbine blade and its Bladed simulation model were set. By calculating fatigue loading, the moment distribution of fatigue test was obtained. Finally, the blade's fatigue loading system driven by an eccentric mass was built and the multi-level amplitude resonant mode was adopted to carry on the test. Almost three months' test results showed that the blade vibrating amplitude was constant, which illustrate the little variation of stiffness of loading point. The stable of stiffness could testify the fatigue life of blade was over 20 years. The results of in-site experiment were basically consistent with the theoretical calculation.
\end{abstract}

Keywords: Fatigue loading test, liner damage cumulative theory, wind turbine blade.

\section{INTRODUCTION}

As one of the key components of wind turbines [1], the blades are affected by the combination of the external environment during operation. The external environment includes blades' own gravity, centrifugal force, gusts of wind and wind shear, etc. [2-5]. Because of alternating loads, fatigue damages have occurred frequently. Researches recently pay more attention on blade's fatigue damage. Fatigue strength analysis currently is an important part of blades design. Wind turbine blades are mainly suffered from the deterministic and random load. When the load exceeds the blade's fatigue limit, the fatigue failure of material occurs. Fatigue failure is a process of accumulation of damage. The S-N curve can be represented in the material under different stress to achieve the failure cycle numbers. But the effect of multistage loading is not considered, but in fact the effect of the multistage loading is very important for the fatigue life [6]. Researching shows that the life of wind turbine blades is largely dependent on its fatigue life [7-9], and fatigue life is determined by the mechanical properties and the size of the force. Because of the complexity of loading, the life assessment of wind turbine blade involves many uncertainties. The simple and practical estimating methods are rare.

For reasons mentioned above, the loading multistage accumulative damage theory was adopted to evaluate fatigue life of Aeroblade1.5-40.3 wind blade. To verify the theoretical calculating, firstly, the coordinates of blades was defined and the according Bladed model was established. Then the moment distribution of fatigue loading was computed. Finally, a fatigue loading system of blade driven by an eccentric mass was built. The loading test carried out in multi-level amplitude resonant mode. The in-site result showed the fatigue life of the blade obtained from theoretical calculating was accurate.

\section{CALCULATION OF BLADE'S FATIGUE LIFE IN THEORY}

Before carrying on fatigue loading test, numerical calculation was applied to evaluate the fatigue life of blade in theory.

\subsection{Linear Cumulative Damage}

In order to obtain the effect of fatigue damage quantitatively, fatigue failure under a certain-level loading $d_{i}$ was defined as:

$d_{i}=\frac{1}{N_{i}}$

where,

$d_{i}$-fatigue failure under a certain-level loading;

$N_{i}$-max cycles of fatigue damage under a certain-level loading. 
In this paper, multi-level loading mode was adopted to test the fatigue life of the blade. Linear cumulative damage theory regards fatigue damage accumulation and the number of cycles as a linear relationship, namely the extent of the damage can be accumulated linearly. When the loading cycles were $n_{i}$, the extent of damage under a certain-level could be expressed as:

$D_{i}=n_{i} d_{i}=\frac{n_{i}}{N_{i}}$

where,

$n_{l}-$ cycles under a certain-level loading

$D_{i}$ - damage accumulation under a certain-level loading.

When the power that material absorbing reached the critical value, the cumulative damage reached a certain threshold, which would cause fatigue failure, the whole damage accumulation $D$ could be expressed as:

$D=\frac{n_{1}}{N_{1}}+\frac{n_{2}}{N_{2}}+\cdots+\frac{n_{k}}{N_{k}}=\sum_{i}^{k} \frac{n_{i}}{N_{i}}=1$

where,

$D$-whole damage accumulation $D$;

$n_{i}, N_{i}$-see Equation (1) and (2)

\subsection{Analysis of Fatigue Properties of FRP}

In order to assess the fatigue life of the blade properly, built the relationships between the load and the life. S-N curve usually be adopted to reflect the relationship between the applied stress and fatigue life. FRP (FiberglassRainforced Plastics) material making of blade generally does not have obvious fatigue limit, the stress under cycling number $N=10^{8}$ can be adopted as fatigue limit. So the fatigue stress $S_{i}$ relative to a certain-level loading in the case of constant-amplitude vibrating mode can be described as:

$S_{i}=\frac{S_{0}}{\sqrt[m]{N_{i}}}$

where:

$S_{i}$ - fatigue stress under a certain -level loading

$N_{l}$ - see equation (1);

$S_{0}$-the stress of $N=1$ (static strength);

$m$-coefficients of Wohler Curve.

(4) can be expressed in logarithmic form.

$\lg S_{i}=\lg S_{0}-\frac{\lg N_{i}}{m}$

According to [10], for FRP material, $\mathrm{m}=10$ and $\mathrm{S}_{0}=255$ MPa. Then the stress levels $S_{i}$ for $N_{i}$ cycles could be obtained, as shown in Fig. (1). (The value of $\mathrm{x}$ coordinate is $\left.\lg N_{i}\right)$.

As seen from Fig. (1). the relation between $S_{i}$ and $\lg N_{i}$ was almost linear. Fatigue analysis of wind turbine blade should base on Fig. (1) to obtain the theoretical fatigue cycling limit.

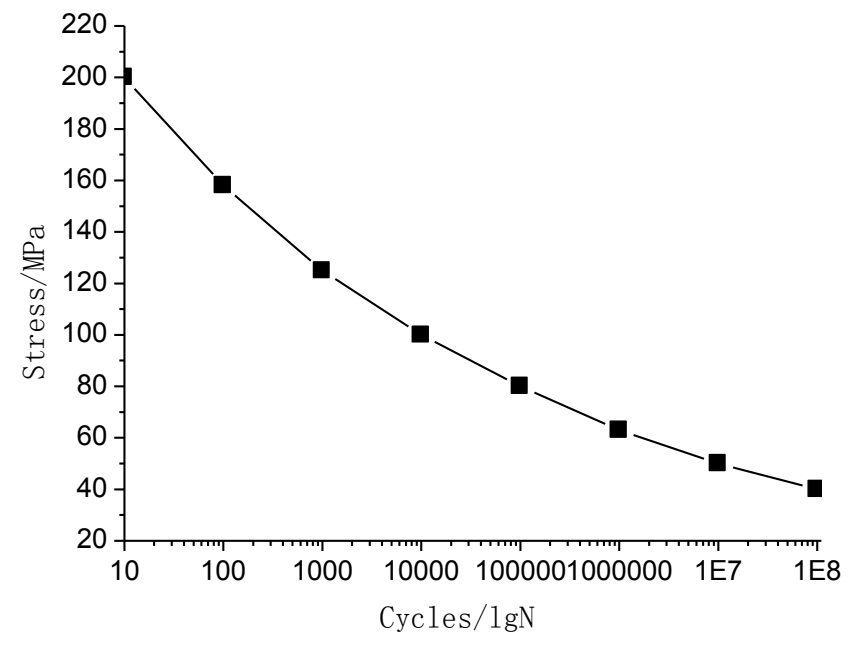

Fig. (1). Fatigue feature curve of FRP material.

\subsection{Calculating Examples}

The total number of cycles $\mathrm{N}$ causing fatigue damage under the actual wind load can be expressed as [11]:

$N=\frac{1}{\sum \frac{\gamma_{i}}{N_{i}}}$

where:

$\gamma_{i}$ - the percentage of stress cycles;

$N_{i}$ - see equation (1).

The fatigue life estimation formula of the wind turbine blade could be expressed as:

$Y=\frac{N}{\left(N_{v} \times \omega \times 60\right)}$

where:

$Y$ - fatigue life expectancy of blade;

$N_{v}$-continuous hours of effective wind speed;

$\omega$-speed of wind wheel.

In this paper, Aeroblade1.5-40.3 (rated power $=1.5 \mathrm{MW}$, blade length $=40.3 \mathrm{~m}$ ) wind turbine blade was applied to calculate fatigue life. Blade material was $45^{\circ}$ biaxial FRP. Because FRP material does not have apparent fatigue limit, according to [12], stress limit $\mathrm{S}_{-1}=40.4 \mathrm{MPa}$, and the base cycles $N_{b}=10^{8}$. The rated wind speed $v=10.4 \mathrm{~m} / \mathrm{s}$ and rated wind wheel $\omega=17.4 \mathrm{rpm}$. The hour distribution values of wind speed and Van-Mieses stress for blade root in vibrating steady state were shown in Table $\mathbf{1}$.

According to fatigue feature curve of FRP material, $N_{i}$ corresponding to every-level stress $S_{i}$ could be obtained. Equation (8)-(10) were the detail computations of fatigue life by using the data of Table 1 .

$N=\frac{1}{\sum \frac{\gamma_{i}}{N_{i}}}=1.88 \times 10^{8}$ 
Table 1. Aeroblade1.5-40.3 wind turbine blade spectrum.

\begin{tabular}{|c|c|c|c|c|}
\hline Wind Speed/m/s & Annual Distribution Hours/h & Stress/MPa & Stress Cycle Percentage $\%$ & Fatigue Life/N \\
\hline \hline 5 & 616.8 & 32.3 & 7.6 & 11.7 \\
\hline 6 & 948.6 & 37.5 & 15.6 & less than the fatigue limit \\
\hline 7 & 1265.0 & 43.4 & 19 & $3.5 \times 10^{7}$ \\
\hline 8 & 1540.7 & 48.7 & 21.9 & $3.7 \times 10^{7}$ \\
\hline 9 & 1775.8 & 55.2 & 24.2 & $1.8 \times 10^{7}$ \\
\hline 10 & 1962.5 & 63.1 & $7 \times 10^{6}$ \\
\hline
\end{tabular}

$N_{v}=\sum n_{i}=8109$

$Y=\frac{N}{\left(N_{v} \times \omega \times 60\right)}=\frac{1.88 \times 10^{8}}{8109 \times 17.4 \times 60} \approx 22.2($ years $)$

The results showed that the fatigue life $t$ of his type blade was above 20 years.

\section{CALCULATION OF BLADE FATIGUE LOADING}

Before carrying on the fatigue in-site test, the fatigue loading needed must be obtained firstly.

\subsection{Coordinate System Definition}

The definition of the blade coordinate system should consider the actual situation, such as in [13-15], authors define different coordinate systems according to the calculation complexity. In this paper, the coordinate origin was defined in the blade root. The coordinates rotated together with the wind wheel, however fixed relative to the boss of wheels. The blade coordinate system and torque $M_{i}$ of each direction were shown in Fig. (2).

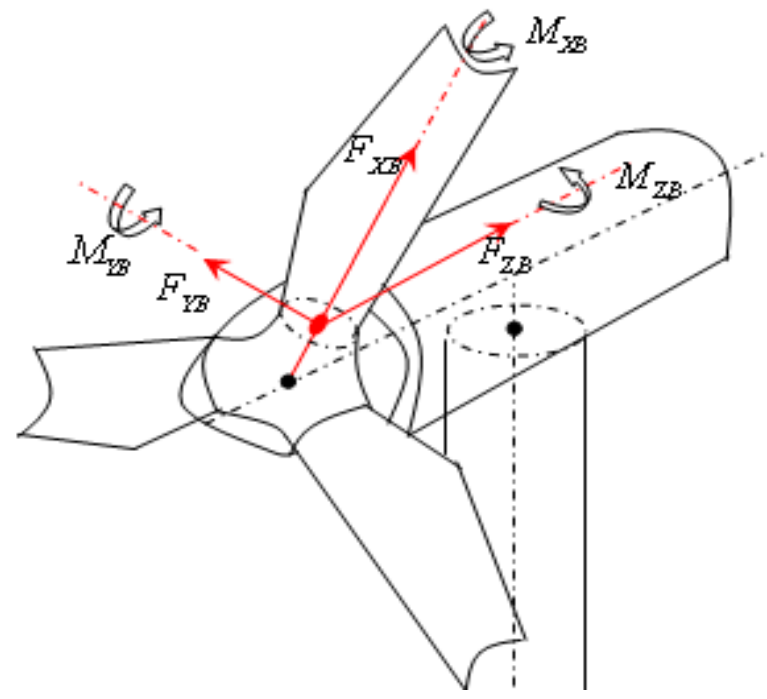

Fig. (2). The coordinate definition of wind wheel.

\subsection{Moment Calculation of Fatigue Loading}

Considering the relation between a blade and whole wind turbine, the basic parameters of the wind turbine were deployed in Table 2.
Table 2. The basic parameters of wind turbine.

\begin{tabular}{|c|c|}
\hline Category & Parameters \\
\hline \hline Air density $/ \mathrm{kg} / \mathrm{m}^{3}$ & 1.225 \\
\hline Rated power/ $\mathrm{MW}$ & 1.5 \\
\hline Rated speed $/ \mathrm{m} / \mathrm{s}$ & 10.4 \\
\hline Control mode & Variable propeller speed \\
\hline Blade number $/$ piece & 3 \\
\hline Wheel diameter $/ \mathrm{m}$ & 82.5 \\
\hline Wheel position & In the direction of the wind \\
\hline Installation angle of blade $/{ }^{\circ}$ & 0 \\
\hline Elevation angle of blade $/{ }^{\circ}$ & 4.5 \\
\hline Cone angle of blade $/{ }^{\circ}$ & 2 \\
\hline Yaw angle $/{ }^{\circ}$ & 0 \\
\hline Cut-in wind speed $/ \mathrm{m} / \mathrm{s}$ & 3 \\
\hline Cut-out of wind speed $/ \mathrm{m} / \mathrm{s}$ & 25 \\
\hline Height of wheel boss $/ \mathrm{m}$ & 80 \\
\hline
\end{tabular}

According to the basic parameters of wind turbine, the Bladed model of wind turbine was established, as shown in Fig. (3).

In Fig. (3), $T$ was elevation angle of blade; $C$ was cone angle of blade; $O$ was the suspension distance of wheel; $L$ was lateral offset distance of blade; $H$ was height of wheel boss.

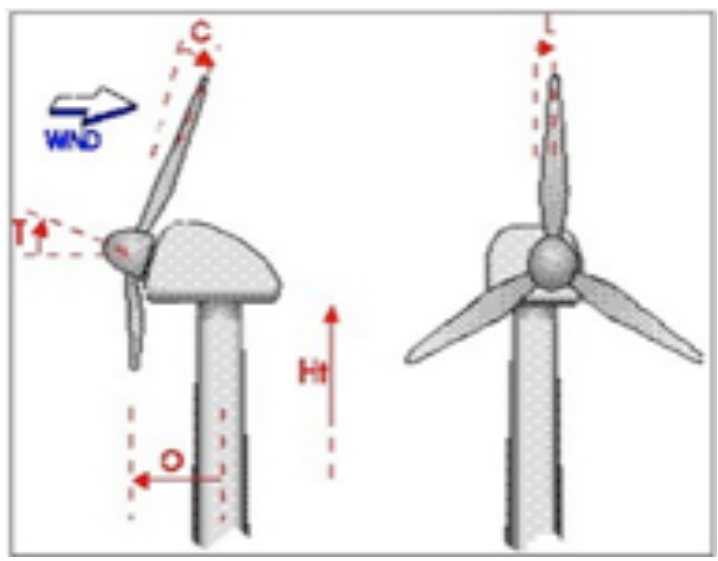

Fig. (3). The bladed model of Aeroblade1.5-40.3. 
Windows for Bladed software was applied to compute the fatigue loading of aeroblade 1.5-40.3. According to GL3A level-load standard, the normal life of the blade is 20 years. In condition of equivalent life was setting for $2.0 \mathrm{E}+6$ cycles, bending moment distribution of flap wise and edgewise direction were obtained, as shown in Fig. (4). Taken the flap wise direction as an computing example, obtained that the flap wise was the main direction bearing wind power and the bending moment of root was larger than $2000 \mathrm{KNm}$.

Blade's fatigue test requires that the bending moment error between computing value and in-site test value along the span-wise of blade is within $7 \%$. However, the distribution of moment is a combined result of blade type and clump weighs. How to arrange clump weighs on blade's surface, see [16]( the first author's thesis).

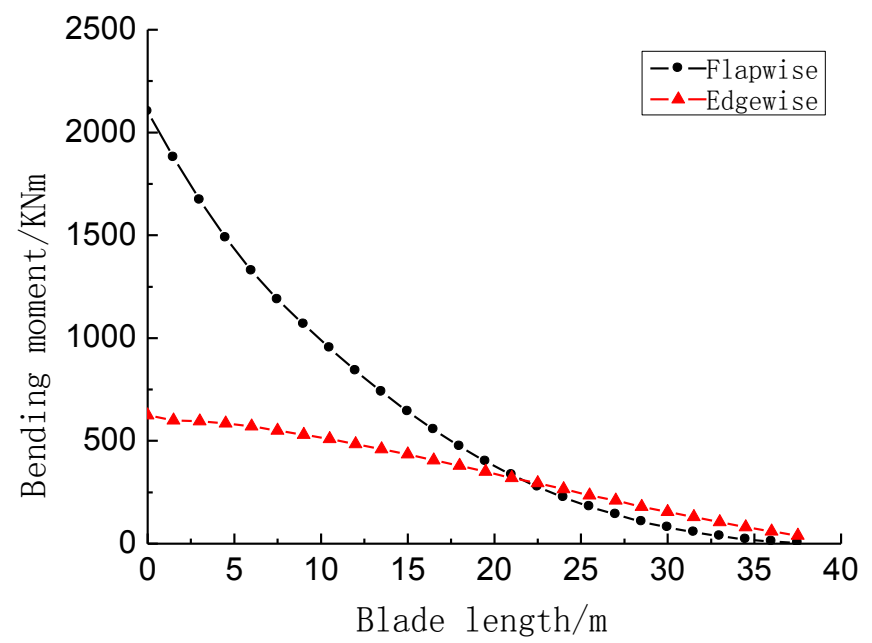

Fig. (4). Moment distribute curve in flapwise and edgewise direction.

\section{FATIGUE LOADING TEST OF WIND TURBINE BLADE}

\subsection{Test Procedure}

The root of blade (Aeroblade1.5-40.3) was fixed on the barrel supporter. The fatigue loading equipment was fastened at the point $(70 \%$ of the blade length along the spanwise direction). The quality of the eccentric mass producing vibrating was $250 \mathrm{~kg}$ and its rotating radius was about $1 \mathrm{~m}$. To ensure the on-site moment matching the calculating moment, a $220 \mathrm{~kg}$ clump weight was fixed at the point along the spanwise direction $27 \mathrm{~m}$. The whole control diagram was shown in Fig. (5). The loading frequency was set by frequency inverter. The blade amplitude was measured by Laser range meter and its data was transferred to Host computer by RS485 bus. The on-site test was shown in Fig. (6) and the test parameters were shown in Table 3.

Multi-level amplitude loading mode was adopted to try to simulate really the power the blade bearing in practice. The outline of fatigue loading test was shown in Table 4 . The amplitude was measured by laser range meter. The loading frequency is set as $0.78 \mathrm{~Hz}$. Open-loop control mode was applied to drive the eccentric mass. The cycle of

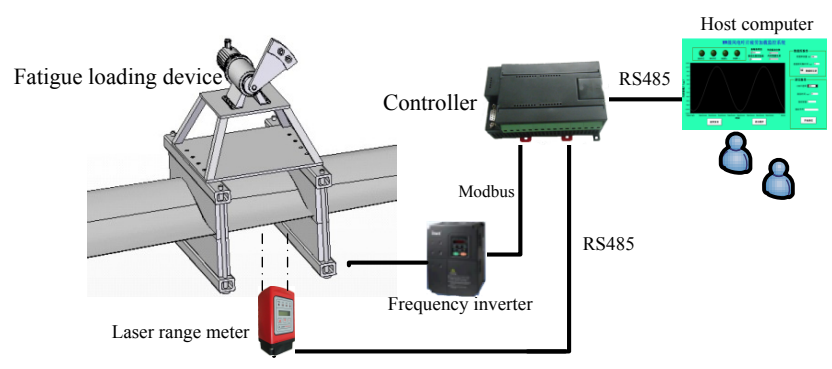

Fig. (5). Control diagram.

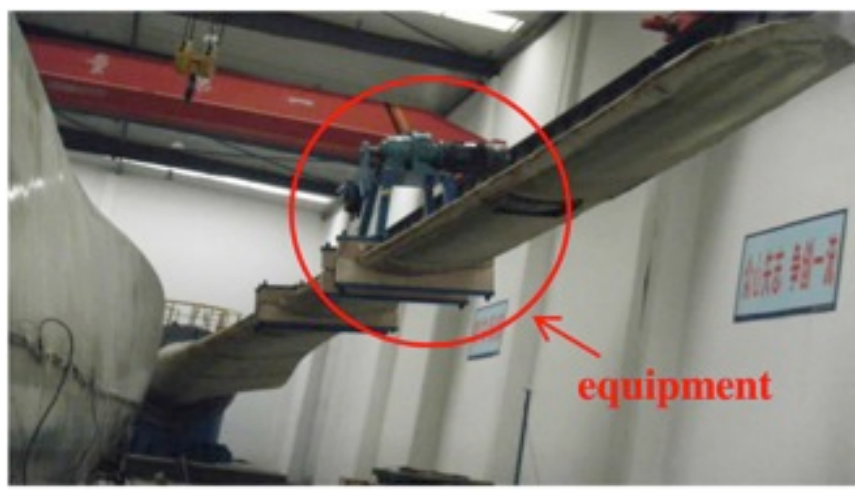

Fig. (6). Aerobalde1.5-40.3 wind turbine blade fatigue loading test.

Table 3. Test parameter.

\begin{tabular}{|c|c|}
\hline Parameters & Value \\
\hline \hline Blade Power & $1.5 \mathrm{MW}$ \\
\hline Blade length & $40.3 \mathrm{~m}$ \\
\hline Blade $1^{\text {st }}$ frequency & $0.78 \mathrm{~Hz}$ \\
\hline Motor power & ABB $22 \mathrm{~kW}$ \\
\hline Eccentric mass & $220 \mathrm{~kg}$ \\
\hline Eccentric length & $1 \mathrm{~m}$ \\
\hline Laser range meter & Leuze-30 \\
\hline Frequency inverter & Shanghai Shenyuan22 KW \\
\hline Encoder & OMRON \\
\hline Proximity switch & CORON \\
\hline
\end{tabular}

fatigue loading test is long and to shorten the test cycle and prevent the blades generating the "exercise effect", high-low loading sequence was adopted in Fig. (7). The loading times were 819200. Because of large data acquisition, Access database was applied to save and manage all data. Vibration frequency and the amplitude of the blade were recorded in real-time.

\subsection{Test Results and Analysis}

Because the blade is in the resonance state in every stage, so the blade amplitude shown as in Fig. (8) is stable. According to IEC61400-23 standard, detecting changes of blade's stiffness is a more reliable method for fatigue damage recognizing. And the changes of blade's stiffness can be judged by the variation of the amplitude. Due to the 
Table 4. Fatigue loading outline.

\begin{tabular}{|c|c|c|c|c|c|c|c|}
\hline Stage & Start Date & End Date & $\begin{array}{c}\text { The Moment of } \\
\text { Root/KNm }\end{array}$ & $\begin{array}{c}\text { Amplitude } \\
/ \boldsymbol{m}\end{array}$ & $\begin{array}{c}\text { Normal } \\
\text { Loading Times }\end{array}$ & $\begin{array}{c}\text { Current Stage } \\
\text { Loading Times }\end{array}$ & \begin{tabular}{c} 
Weight \\
\hline 1
\end{tabular} \\
\hline \hline $2014-02-15$ & $2014-02-18$ & 3040 & 1.75 & 120000 & 19200 & 0.16 \\
\hline 3 & $2014-02-19$ & $2014-02-24$ & 2862 & 1.48 & 250000 & 40000 & 0.16 \\
\hline 4 & $2014-02-25$ & $2014-03-11$ & 2706 & 1.35 & 500000 & 130000 & 0.26 \\
\hline 5 & $2014-03-12$ & $2014-03-31$ & 2580 & 1.25 & 1000000 & 180000 & 0.18 \\
\hline
\end{tabular}

limitation of space, only partial results of fatigue load tests were given, for example, the peak value of amplitude at fifth stage, as shown in Fig. (9).

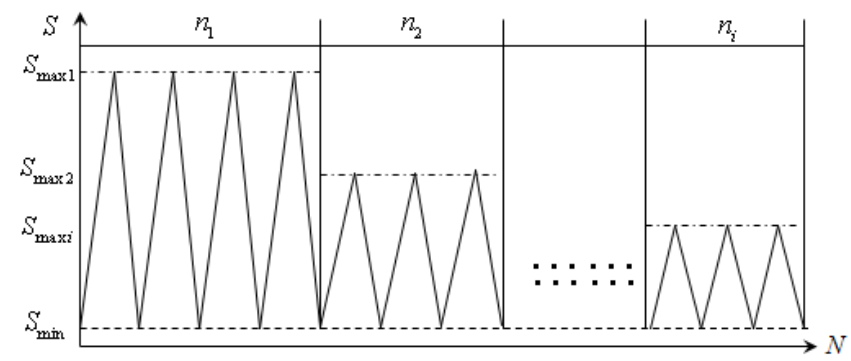

Fig. (7). Aerobalde1.5-40.3 wind turbine blade high-low loading sequence.

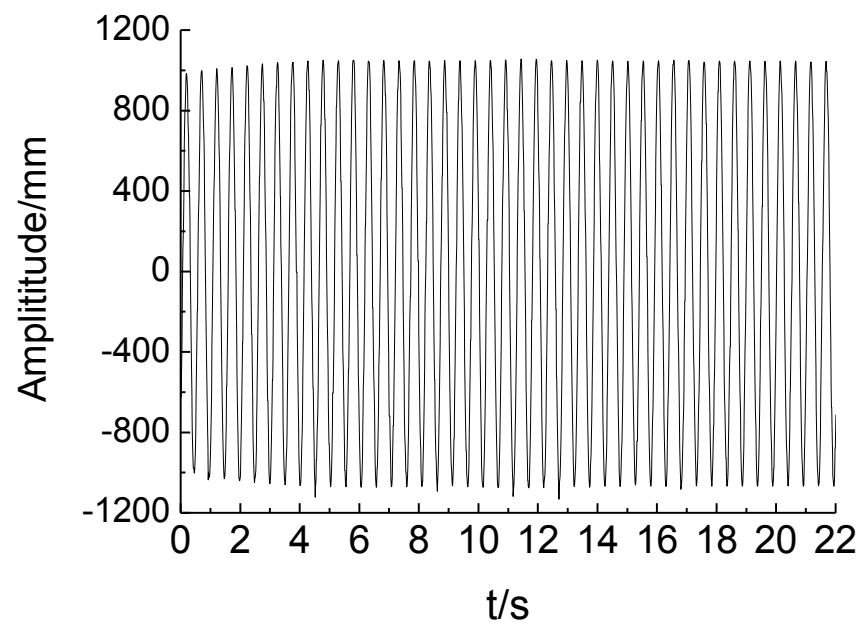

Fig. (8) Wind turbine blade amplitude vary curve.

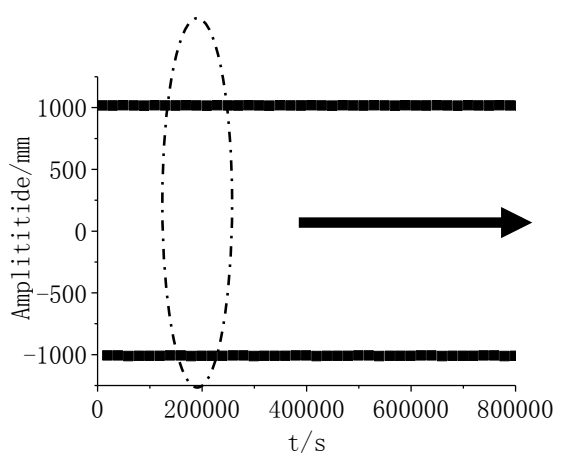

Fig. (9). Wind turbine blade peak-peak variable curve.
In Fig. (9), the peak value of amplitude maintained around at $1000 \mathrm{~mm}$. The error was within $\pm 3 \%$, which indicate that the stiffness of the blade did not have large changing. The phenomenon verified that the fatigue life of the blade was over 20 years.

The frequency statistics of the root's bending moment was made, as shown in Fig. (10). To see clearly, the number of $\mathrm{x}$-coordinate was the ratio of actual moment value to the set value. As we could see form Fig. (10), the amplitude of loading point was stable because of reasonable layout of clump weight. The error of the bending moment for blade root did not exceed $\pm 0.4 \%$.

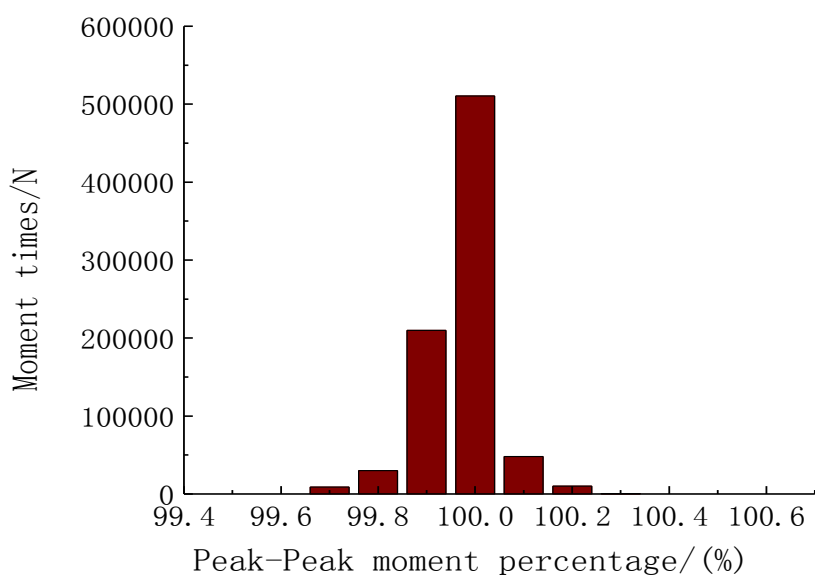

Fig. (10). Wind turbine blade root moment statistic picture.

\section{CONCLUSION}

Fatigue life assessment is a significant aspect for the design of wind turbine blade. Theoretical calculations and

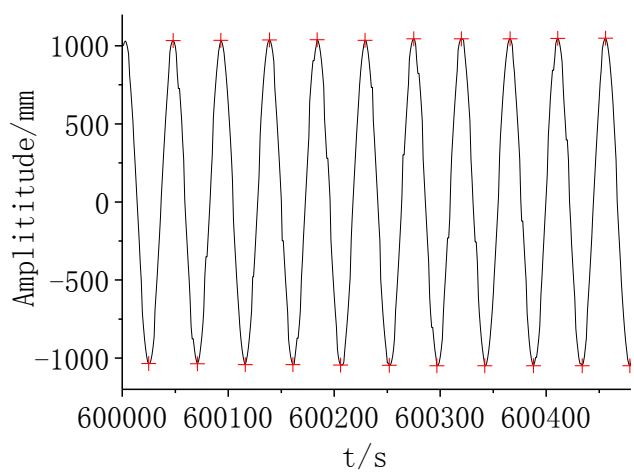


experimental verification were both applied to evaluate the fatigue life of Aeroblade1.5-40.3 wind turbine blade. Conclusions can be drawn as follows:

(1) By analyzing the properties of FRP materials, obtained that FRP's fatigue feature curve was almost linear for stress and logarithmic form of cycles. Based on the multistage loading accumulative damage theory, the fatigue life of Aeroblade1.5-40.3 wind turbine blade was calculated over 20 years.

(2) The Bladed model of whole wind turbine was established. According to actual bearing of blade, the number of loading times was set and the distribution of blade's bending moment was obtained by computing in simulating method. These works laid the foundation for the subsequent fatigue tests in-site.

(3) The amplitude of loading point kept stable in whole test, which testify that the fatigue life was over 20 years. The result of in-site test was consistent with the result of computing, which verify the correctness of evaluating method for blade's fatigue life.

(4) The fatigue test system constructed in this paper was simple but had strong stability. Open-loop control mode could ensure the accuracy of test effectively. This testified the feasible of controlling method applied to blade's fatigue loading test.

\section{CONFLICT OF INTEREST}

The authors confirm that this article content has no conflict of interest.

\section{ACKNOWLEDGEMENTS}

This work is sponsored by National Natural Science Foundation of China (No. 51405275), National Natural Science Foundation of China (No.51305243), and Shandong provincial Natural Science Foundation, China (No. ZR2014EL027).

\section{REFERENCES}

[1] J. Chen, and X. Wang, W. Shen, W. J. Zhu1, and N. S. Jens, "Optimization design of blade shapes for wind turbines," Journal of Mechanical Engineering, vol.46, no.3, pp.131-134, 2010.

[2] L. Lu, H. Yang, and J. Burnett, "Investigation on wind power potential on Hong Kong islands: An analysis of wind power and wind turbine characteristics," Renewable Energy, vol.27, no.1, pp.1-12, 2002.

[3] G. M. J. Herbert, S. Iniyan, E. Sreevalsan, and S. Rajapandian, "A review of wind energy technologies," Renewable Sustainable Energy Reviews, vol.11, no.6, pp.1117-1145, 2007.

[4] C. Kong, J. Bang, and Y. Sugiyama, "Structural investigation of composite wind turbine blade considering various load cases and fatigue life," Wind Energy, vol.30, pp.2101-2114, 2005.

[5] C. Li, Study on CFD Simulation of Turbulence Wind Field Near Ground, Harbin:Harbin Institute of Technology, pp.18-22, 2010.

[6] X. Wang, N. Hong, "Study on fuzzy miner rule considering loading sequence," China Mechanical Engineering, vol.22, no.19, pp.27252728, 2008.

[7] G. He, "Rotationnally sampled spectrum and fatigue life prediction of wind turbine system," Journal of Harbin Institute of Technology, vol.42, no.5, pp.816-819, 2008.

[8] H. J. Sutherland, and J. F. Mandell, "The effect of mean stress on damage predictions for spectral coupons," Wind Energy, vol.8, pp.93-108, 2005.

[9] C. W. Kensche, "Fatigue of composites for wind tuebines," The $3^{\text {rd }}$ International Conference on Fatigue of Composites, vol.9, pp.1-21, 2004.

[10] P. Zhou, J. Zeng, J. Xiao, and F. S. Tan, “Aerodynamic analysis of a large-scale wind turbine blade based on bladed software," Journal of Central South University, vol.41, no.5, pp.2022-2027, 2010.

[11] D. Li, Z. Ye, Y. Chen, C. Yan, and N. Bao, "Load spectrum and fatigue life analysis of the balde of horizontal axis wind turbine," Engineering Mechanics, vol.21, no.6, pp.118-123, 2004.

[12] D. Li, Z. Ye, Y. Chen, and N. Bao, "Fatigue life analysis of the glass reinforced plastic blade of horizontal axis wind turbine," Acta Energiae Solaris Sinca, vol.25, no.5, pp.592-597, 2004.

[13] X. Liu, X. Zhang, G. Li, C. Yan, and Z. Ye. "Dynamic response analysis of the blade of horizontal axis wind turbine," Journal of Mechanical Engineering, vol.46, no.12, pp.128-134, 2010.

[14] A. Jorge, and V. Ale, "Aerodynamic loads and fatigue of small wind turbine blades standards and testing procedures," Europe Wind Energy Event, vol.3, pp.14-17, 2011.

[15] M. Noda, and R. G. J. Flay, "A simulation model for wind turbine blade fatigue loads," Journal of Wind Engineering and Industrial Aerodynamics, vol.83, pp. 527-540, 1999.

[16] L. Zhang, Research on Key Technology of MW Wind Turbine Blade Loading System, Tong ji University: Shanghai, pp.104-108, 2012. 